\title{
ENSEÑAR EL APRENDER. PIDIENDO UNA EDUCACIÓN SOCRÁTICA DESDE DENTRO.
}

\section{TEACH LEARNING. ASKING FOR A SOCRATIC EDUCATION FROM WITHIN.}

\author{
Antonio Gutiérrez-Pozo ${ }^{1}$ \\ Universidad de Sevilla, España
}

\begin{abstract}
Resumen: La educación es un problema esencial de la filosofía porque la filosofía es razón práctica, educación del alma. La educación tradicional se ha basado en el enseñar, es decir, en el profesor y en los contenidos que explica. Pero la pedagogía socrática se centra en el alumno y en el aprender. En esta praxis educativa sin embargo la función del maestro es primordial. Tiene que enseñar al alumno a aprender por sí mismo, desde dentro. Su papel es ayudar al alumno a descubrir los contenidos, en vez de dárselos directamente desde fuera. Para ello el maestro tiene que convertir la pregunta en método pedagógico. Pero entonces enseñar es más difícil que aprender. Contra el intelectualismo, el fundamento de esta pedagogía es una comprensión más práctica y vitalista del saber.
\end{abstract}

Palabras clave: Sócrates; Saber; Aprender; Enseñar; Preguntar; Descubrir.

\begin{abstract}
Education is an essential problem of philosophy because philosophy is practical reason, education of the soul. Traditional education has been based on teaching, that is, on the teacher and the contents that explains. But Socratic pedagogy focuses on the student and learning. In this educational practice, however, the role of the teacher is primordial. He has to teach the student to learn by himself, from within. His role is to help the student to discover the contents, instead of giving them directly from outside. To do this, the teacher has to convert the question into a pedagogical method. But then teaching is more difficult than learning. Against intellectualism, the foundation of this pedagogy is a more practical and vitalist understanding of knowledge.
\end{abstract}

Key words: Sócrates; Knowledge; To learn; To teach; To ask; To discover.

\section{Introducción: pedagogía y filosofía}

El animal ya es lo que ha de ser por el instinto, pero el ser humano tiene que hacerse pues, nos advierte Kant (1765, p. 441), "llega sin cultivo (roh) al mundo", de manera que "es la única criatura (Geschöpf) que debe ser educada". Necesita educación porque, añade, "el ser humano puede llegar a ser humano exclusivamente a través de la educación” (KANT, 1765, p. 443). El ser humano por tanto no es humano sin más; más bien, la educación es la que le hace ser, la que lo verifica en su humanidad. Por otra parte, el propio fenómeno educativo implica que el ser humano individual no puede hacerse a sí mismo, sino que los otros tiene que ayudar a construirlo. La pedagogía es asunto de la sociedad y siempre se manifiesta como pedagogía social. Una sociedad despreocupada por la educación no puede tener otro destino que la deshumanización de sus componentes y de ella misma en su totalidad. Dada su importancia para el bienestar de la sociedad

\footnotetext{
${ }^{1}$ Doctor en Filosofía por la Universidad de Sevilla, España, profesor titular de la Facultad de Filosofía de la Universidad de Sevilla. E-MAIL: agpozo@us.es. ORCID: http://orcid.org/0000-0003-4143-1854.

Revista Tópicos Educacionais, Pernambuco, v. 27, n. 01, p. 136-153, 2021. ISSN: 2448-0215.

https://periodicos.ufpe.br/revistas/topicoseducacionais/index 
y el estado, Aristóteles ya expuso la necesidad de que el gobernante la atienda: "El legislador debe ocuparse sobre todo de la educación de los jóvenes, nadie lo discutiría. De hecho, en las ciudades donde no ocurre así, eso daña los regímenes” (ARISTÓTELES, 1988, 1337a 1-5, p. 455). Más de dos mil años después, Dewey (1897, p. 29) insiste en su bondad social para el desarrollo humano: "La educación es el método fundamental del progreso y de la reforma social". Para lograrlo, lo que la educación debe proporcionarnos es, en resumen y en palabras de Unamuno: "Alma de tolerancia; mente hospitalaria, culto a la verdad, sintiéndola viva, proteica y multiforme; comprensión de las más opuestas concepciones, abierta; odio al formalismo; atención al pueblo; heroísmo de trabajo; sumersión en la realidad concreta, fija la vista a la más alta idealidad abstracta" (UNAMUNO, 1899, pp. 117s). Ahora bien, el primer requisito para que la educación sea valiosa es creer realmente en ella, considerarla de verdad necesaria: "Hay que crear fe, fe verdadera en la enseñanza, y sólo se crea esta fe enseñando con ella, con fe viva. La mayor obra de la enseñanza aquí estriba en enseñar su propia imprescindibilidad”, escribía Unamuno (1899, p. 64) para quejarse inmediatamente de que la educación española de entonces "mata el apetito de aprender". Por todo esto es obvio que, en palabras de Heidegger (1951/52, p. 18), resulta "algo sublime (hohen Sache) llegar a ser maestro (Lehrer)", aunque "hoy, cuando todas las cosas se valoran hacia abajo y desde abajo, desde el punto de vista mercantil (vom Geschäft), ya nadie quiere ser maestro".

La aproximación que presentamos a la cuestión pedagógica es de orden filosófico. La legitimación de semejante acercamiento no se debe sólo a la relevancia social e individual de la educación. La atención que la filosofía desde su inicio ha dedicado a la pedagogía tampoco es meramente accidental ni simple consecuencia de la voluntad sistemática que caracteriza a la filosofía como saber y que le impulsa a tratar todas las dimensiones de lo real, incluido el ámbito educativo. Suele entenderse la filosofía de la educación como una "aproximación al mundo de los fenómenos educativos empleando la metodología propia de la Filosofía” (GARCÍA AMILBURU, GARCÍA GUTIÉRREZ, 2012, p. 13). Esta definición, perfectamente exportable a la filosofía de la ciencia o del lenguaje o de la historia, presupone la existencia de una distancia de indiferencia entre la filosofía y cada objeto de estudio. Dada su aspiración de universalidad, la filosofía lo mismo trata sobre una cosa que sobre otra, pero considerados en sí mismos le es indiferente la educación, la historia, la ciencia o el lenguaje, puesto que no parece haber ningún vínculo especialmente relevante con esos objetos. A diferencia de esta posición, creemos que la relación entre filosofía y pedagogía es más significativa. La educación no es un tema de estudio más para la Revista Tópicos Educacionais, Pernambuco, v. 27, n. 01, p. 136-153, 2021. ISSN: 2448-0215. https://periodicos.ufpe.br/revistas/topicoseducacionais/index DOI: 10.51359/2448-0215.2021.249623 
filosofía. Hay un nexo esencial entre pedagogía y filosofía que justifica -exige- el tratamiento filosófico de la educación. Dewey insiste en que "hay una íntima y vital relación entre la necesidad de filosofía y la necesidad de educación" y ello se debe, añade, a que la filosofía ofrece una comprensión de "modo mejor de vida" (DEWEY, 1912/13, pp. 298, 306s). Más que pura teoría, la filosofía, animada por una voluntad pedagógica, es razón práctica, "cuidado (educación) del alma" estableció Platón (PLATÓN, 1985, 30b, p. 168). Si la educación tiene un papel especialmente relevante en la filosofía es porque la propia filosofía es educativa. La filosofía no puede evitar ser educadora, pedagogía social, configuración de una vida social más humana. No es casualidad que Sócrates, "el más puro pensador de Occidente" en palabras de Heidegger (1951/52, p. 29), considerara su quehacer como filósofo y como educador como uno y el mismo. La dimensión artística que indudablemente también posee la educación no puede impedir la reflexión filosófica sobre ella que vamos a exponer. Precisamente porque creía que "la educación es un arte", Dewey se preguntaba si “podía haber una ciencia de la educación” (DEWEY, 1929, pp. 3, 6s). Es indudable que educar tiene mucho de arte porque se aprende a educar educando, en la práctica educativa misma, razón por la que nunca se logra aprender del todo y la misma praxis ejerce de maestra. Ya Kant había advertido que "la educación (Erziehung) es un arte (Kunst) cuyo ejercicio (Ausübung) debe ser mejorado mediante muchas generaciones" (KANT, 1765, p. 446). Pero esto último no puede suspender la atención filosófica sobre esa actividad artística de educar. Más bien y lejos de estar al margen de la praxis, esa teoría no sólo se va descubriendo en el ejercicio mismo del arte de educar, sino que contribuye a su progreso.

\section{Pedagogía paidocéntrica: educar desde dentro}

Nuestra consideración filosófica del hecho educativo empieza con una sencilla evidencia sobre su configuración. Está compuesto por tres elementos: el maestro que enseña, el contenido que hay que enseñar y el alumno que aprende, el enseñado. Aunque Rousseau y Pestolazzi se opusieron, la pedagogía dominante tradicional centró la experiencia educativa en el maestro (pedagogía magistocéntrica) y en los contenidos por enseñar (pedagogía logocéntrica), y relegó al segundo plano al alumno, convertido en mero receptor pasivo. Recuperando el hilo rojo que anuda la corriente más fértil de la historia filosófica de la pedagogía cuyo origen se halla en Sócrates, nuestra propuesta retoma la dirección rousseauniana que pretende que el alumno sea más activo. Ortega escribe que se trata simplemente de "trasladar el fundamento de la ciencia pedagógica del maestro y del saber al discípulo y reconocer que son éste y sus condiciones peculiares lo único que Revista Tópicos Educacionais, Pernambuco, v. 27, n. 01, p. 136-153, 2021. ISSN: 2448-0215. https://periodicos.ufpe.br/revistas/topicoseducacionais/index DOI: 10.51359/2448-0215.2021.249623 
puede guiarnos para construir un organismo con la enseñanza" (ORTEGA, 1930, p. 544). Contra la pedagogía magistocéntrica, basada en el profesor como emisor de contenidos, y contra la pedagogía logocéntrica, fundada sobre los contenidos o logoi que el profesor luego trasmite, el modelo socrático que adoptamos representa un giro copernicano pedagógico porque hace descansar el proceso educativo sobre el alumno, constituyéndose como una pedagogía paidocéntrica. Ciertamente, tanto el término 'pedagogía' como el de 'educación' hacen referencia a una actividad de llevar, conducir y guiar 'desde fuera'. En efecto, el paidagogos no era el maestro en la antigua Grecia sino el esclavo cuya misión era llevar los niños al maestro, a la escuela. Educar, enseñar, en este sentido es conducir desde fuera. Pero no podemos olvidar que 'educación' también conecta con eductio, que significa extraer, sacar hacia fuera. Nuestra propuesta pedagógica de naturaleza socrática está directamente vinculada con esta segunda acepción del término 'educar'. A diferencia de la educación desde fuera, desde el maestro o desde los contenidos, la pedagogía paidocéntrica y socrática se realiza desde dentro, desde el alumno como nuevo centro de la educación. No pedimos 'desde dentro' una educación sino que pedimos una educación 'desde dentro', radicada en el alumno y no impuesta 'desde fuera' de él. En el fondo no hay enseñanza 'desde fuera', sino que verdaderamente sólo la hay si es realizada desde dentro del propio alumno.

La primacía del contenido y el profesor hacía de la educación tradicional, de corte intelectualista, una pedagogía del enseñar, mientras que la valoración del alumno ha sido la causa de una pedagogía del aprender. Es absurdo concebir el enseñar del profesor sin tener en cuenta el aprender del alumno. Tampoco se puede separar el contenido de su enseñanza ni, sobre todo, de su aprendizaje. El giro entonces consiste en pasar el acento del verbo 'enseñar' como verbo pedagógico principal al verbo 'aprender' como nuevo verbo predominante de la pedagogía. La consecuencia de este giro pedagógico practicado ya por Sócrates es que los contenidos, el saber, no pueden ser enseñados sin más, sino que han de ser aprendidos, lo que implica darle a la pedagogía un carácter más empírico o experiencial. No se trata, pues, de enseñar/trasmitir unos contenidos. Ya Unamuno advirtió que procuraba "no sólo enseñar la materia que me está encomendada, sino disciplinar y avivar la mente de mis alumnos, obrar sobre cada uno de ellos" (UNAMUNO, 1902, p. 519). La educación se centra en la experiencia del aprendizaje. La pedagogía paidocéntrica puede calificarse también como empiriocéntrica. Los conceptos han de conformarse a las experiencias e intuiciones de los alumnos. Para Schopenhauer "los conceptos deben surgir de las intuiciones mediante abstracción”, y de ahí deduce que existe, por un lado, una Revista Tópicos Educacionais, Pernambuco, v. 27, n. 01, p. 136-153, 2021. ISSN: 2448-0215. https://periodicos.ufpe.br/revistas/topicoseducacionais/index DOI: 10.51359/2448-0215.2021.249623 
“educación natural", que consiste en aprender de la experiencia, de modo que en esta educación existe una perfecta armonía entre conceptos y experiencias, pues aquéllos brotan de éstas, y, por otro, una "educación artificial" en la que la mente está "repleta de conceptos antes de que exista cualquier conocimiento amplio del mundo intuitivo", de manera que "tenemos la cabeza llena de conceptos que nos esforzamos en aplicar pero que casi siempre ponemos al revés" (SCHOPENHAUER, 1851, § 372, p. 639). En esta mala educación artificial de naturaleza magistocéntrica y logocéntrica, "en oposición directa al desarrollo natural de nuestro espíritu, recibimos primero los conceptos y al final las intuiciones; porque los educadores, en lugar de desarrollar en el muchacho la capacidad misma de conocer, juzgar y pensar, se empeñan sólo en llenarle la cabeza de pensamientos ajenos y acabados" (SCHOPENHAUER, 1851, § 372, p. 640).

\section{Pedagogía de la alusión: aprender haciendo}

El paidocentrismo implica que el alumno ha de aprender él mismo, que sólo aprende haciendo, pensando, descubriendo, experimentado por él mismo, y no mediante la pasiva recepción de contenidos. Esta educación empirista de origen socrático se encuentra expresada en el lema pedagógico de Dewey aprender haciendo (learn by doing): "Se puede aprender haciendo algo que no se comprende" (DEWEY, 1916, p. 84). Esta filosofía educativa de la praxis se remonta a Aristóteles. Igual que en ética lo esencial según Aristóteles (1959, 1103a-b, pp. 19s) no es edificar una "pura teoría (...) para saber lo que es la virtud", sino "hacernos virtuosos y buenos", en pedagogía no se trata de saber qué es educar, ni hacer teoría pedagógica, sino de enseñar y aprender efectiva y adecuadamente. Aristóteles sostiene que "no adquirimos las virtudes sino después de haberlas previamente practicado", porque "en las cosas que no se pueden hacer sino después de haberlas aprendido no las aprendemos sino practicándolas, y así uno se hace arquitecto construyendo, se hace músico componiendo, y uno se hace justo practicando la justicia" (ARISTÓTELES, II, 1, 2, pp. 87s). Lo mismo ocurre en esta pedagogía paidocéntrica empirista. Heidegger (1952, p. 138) sostiene que "nunca aprenderemos a nadar gracias a un tratado sobre la natación" sino nadando, ni llegaremos a ser buenos mediante un tratado de moral sino realizando actos virtuosos. Del mismo modo no aprenderemos lo por aprender si se nos da sin más, sino que tenemos que aprenderlo nosotros descubriéndolo y apropiándonos de ello. Cuando Kant afirma que "nunca puede aprenderse la filosofía" y que "sólo se puede aprender a filosofar, a ejercitar el talento de la razón" (KANT, 1787, B 865-866, pp. 541s), no sólo quiere decir que, dado que la filosofía no es una doctrina ya hecha y terminada, no se la puede aprender y que en esa situación Revista Tópicos Educacionais, Pernambuco, v. 27, n. 01, p. 136-153, 2021. ISSN: 2448-0215. https://periodicos.ufpe.br/revistas/topicoseducacionais/index DOI: $10.51359 / 2448-0215.2021 .249623$ 
sólo podemos pensar filosóficamente, sino que sobre todo quiere decir que la clave del aprendizaje está en la práctica, en la actividad. Aprender los contenidos de la historia de la filosofía es importante y muy útil, pero lo que realmente vale es aprender a pensar porque sólo así prenderemos de verdad los contenidos filosóficos. La clave del aprender está en el alumno, que sólo aprende haciendo él mismo, aprendiendo. En palabras de Gadamer (2000, pp. 11, 16), "la educación es educarse (sich erziehen)", y por tanto a la pregunta de quién educa sólo se puede responder que "nos educamos a nosotros mismos". Ya Lessing había afirmado que "la educación no le da al ser humano nada que él no pueda tener por sí mismo" (LESSING, 1780, p. 490). Se aprende mediante la acción. Si no es así de nada vale todo lo que el maestro pueda enseñar.

Ahora bien, el paidocentrismo no supone olvidar el saber ni al maestro, el cual seguirá enseñando contenidos pero con otro método, un método basado en el aprender del alumno. Ni deprecia la labor del maestro ni le resta responsabilidad. Al contrario. El maestro ahora no es el que imparte la lección, el que enseña la verdad, sino el que ayuda al alumno a aprenderla por sí mismo. Lo que enseña al alumno es a que él mismo 'aprenda haciendo'. Se trata de un maestro socrático. Aunque el alumno se educa a sí mismo, necesita de la ayuda del maestro que, como una partera, le ayuda a descubrir en sí mismo los conocimientos. La educación es un ejercicio del propio alumno y la misión del maestro es fomentar y dirigir esta actividad de descubrimiento que es aprender. Ortega nos ha dejado un texto fundamental de esta pedagogía del aprender que él llama pedagogía de la alusión:

"Quien quiera enseñarnos una verdad que no nos la diga: simplemente que aluda a ella con un breve gesto, gesto que inicie en el aire una ideal trayectoria, deslizándonos por la cual lleguemos nosotros mismos hasta los pies de la nueva verdad (...) Quien quiera enseñarnos una verdad, que nos sitúe de modo que la descubramos nosotros" (ORTEGA, 1914, pp. 768s).

El aprender haciendo en educación supone una pedagogía del descubrimiento. Esta pedagogía no va contra los contenidos, pero éstos deben ser enseñados prácticamente: no hay que 'darlos' sino 'mostrarlos'. El maestro sólo los alude, o sea, debe iniciar el movimiento de su descubrimiento para que lo acabe el alumno. Para enseñar una verdad al alumno, no hay que decirla, hay que aludirla. El maestro socrático debe ayudarle a que la descubra porque sólo así verdaderamente la aprende. Y sólo así enseña en sentido estricto. Se enseña por alusiones.

\section{Pedagogía vitalista: enseñar la necesidad del saber}


Antes de profundizar y precisar la relación filosófica entre el aprender y el enseñar que de aquí se desprende, reparemos en que lo que le da sentido a esta pedagogía del descubrimiento es, contra el intelectualismo, la afirmación de la dimensión vitalista del saber. Conviene aclarar que hay dos comprensiones extremas del vínculo existente entre la teoría y la vida, el saber y la experiencia: el intelectualismo o idealismo y el vitalismo radical. A la postura filosófica idealista y abstracta, antivital, que considera que la teoría es algo autónomo y puramente intelectual que surge de la conciencia y no de la experiencia vital, Nietzsche (1889a, p. 264) le responde que "sólo tienen valor los pensamientos caminados", esto es, los pensamientos vividos; los pensamientos y conceptos que surgen de la experiencia de la existencia. Según Unamuno, no hay realmente idea ni conciencia puras, abstractas, alejadas de la existencia real: "El hecho primordial es que la curiosidad brotó de la necesidad de conocer para vivir" (UNAMUNO, 1912, p. 150). Contra el intelectualismo, no se legitiman las ideas por sí mismas, ni se vive para ellas, subordinando la vida a la idea, sino que Unamuno (1912, p. 150) reclama que se busque "la vida en la verdad", o sea, que las ideas valgan para vivir. Se trata, concluye Unamuno, de "vivir todas las ideas para con ellas enriquecerme yo", de manera que hay que usar las ideas para servir a la vida y no al revés, pues, añade, “quiero ser su dueño- no su esclavo" (UNAMUNO, 1900, p. 430). Porque no es la ciencia la que nutre el vivir y le da sentido, sino al revés, la vida es la que alimenta y soporta la ciencia y la cultura en general. Pensar no es un mero ejercicio intelectual. Ante todo es un acto vital. Reducir las ideas a asuntos meramente intelectuales equivale a matarlas. Así, los griegos, según indica Heidegger, "luchaban por comprender y por ejercer el cuestionar contemplativo (theoria) (betrachtende Fragen) como una forma de la energeia", de modo que "entienden la teoría misma como la suprema realización (höchste Verwirklichung) de una auténtica praxis" (HEIDEGGER, 1933, p. 110).

La vida no puede garantizar la verdad objetiva del conocimiento, pero sí es la fuente del conocer, de donde se deduce que la teoría sólo vale cuando se funda sobre la experiencia vital. En este mismo sentido, Ortega afirma no creer más que en "los pensamientos de los náufragos", de manera que sólo tienen valor los conceptos que brotan del naufragio vital (ORTEGA, 1932, p. 122). La enseñanza no puede ser ajena a esta vitalización del saber que niega que los pensamientos sean objetos meramente teóricos y afirma que sólo valen vitalmente si son vividos, caminados. Carece entonces de sentido aprender contenidos directamente enseñados -trasmitidos- por el profesor, pues a este aprender le faltaría la dimensión vital. En rigor, no sería aprender, pues aprender realmente un contenido significa vivirlo, descubrirlo y no sólo recibirlo en la conciencia. Revista Tópicos Educacionais, Pernambuco, v. 27, n. 01, p. 136-153, 2021. ISSN: 2448-0215. https://periodicos.ufpe.br/revistas/topicoseducacionais/index DOI: 10.51359/2448-0215.2021.249623 
Como expuso Ortega en clave socrática, una verdad enseñada sólo tiene sentido para el alumno si éste vive la experiencia de su descubrimiento. Ahora bien, para descubrirla hay que buscarla, pero sólo se busca lo que se necesita. Este vínculo esencial entre aprender/enseñar, descubrir, buscar y necesitar permite a Ortega profundizar en la naturaleza del estudiar y extraer relevantes consecuencias pedagógicas.

De hecho, la traducción pedagógica de la desintelectualización y vitalización del origen del saber la expone el propio Ortega (1933, p. 267) cuando sostiene que, "en general, estudiar sería una falsedad". Ello se debe a que las verdades que componen una ciencia fueron encontradas originariamente por unos seres humanos creadores, "pero si las encontraron es que las buscaron, y si las buscaron es que las habían menester, que no podían, por unos u otros motivos, prescindir de ellas", de manera que se puede afirmar que "hemos encontrado una verdad cuando hemos hallado un cierto pensamiento que satisface una necesidad intelectual previamente sentida por nosotros", de donde se desprende que "verdad es, por tanto, aquello que aquieta una inquietud de nuestra inteligencia. Sin esta inquietud no cabe aquel aquietamiento" (ORTEGA, 1933, p. 268). Esta teoría pedagógica del estudiar destaca la gran diferencia que hay entre el creador y el estudiante. El deseo de ciencia que puede tener el buen estudiante nada tiene que ver con la situación espiritual del que la descubrió, pues "éste no se encontró primero con ella y luego sintió la necesidad de poseerla, sino que primero sintió una necesidad vital y no científica y ella le llevó a buscar su satisfacción, y al encontrarla en unas ciertas ideas resultó que éstas eran la ciencia. En cambio, el estudiante se encuentra con la ciencia ya hecha", que luego puede gustarle e incluso sentir que la necesita, "pero nada de esto tiene que ver con la necesidad auténtica que lleva a crear la ciencia", porque "la necesidad auténtica existe sin que tenga que preexistir ni en la imaginación aquello que podría satisfacerla. Se necesita justo lo que no se tiene, lo que falta" (ORTEGA, 1933, p. 270). Frente al creador que busca la ciencia por necesidad, el estudiante, precisamente porque pretende la ciencia sin necesitarla, "tenderá a no hacerse cuestión del contenido de la ciencia, a no criticarla; al contrario, tenderá a reconfortarse pensando que ese contenido de la ciencia ya hecha tiene un valor definitivo, es la pura verdad", mientras que "el menesteroso de una ciencia, el que siente la necesidad de la verdad, se acercará cauteloso al saber ya hecho sometiéndolo a crítica" (ORTEGA, 1933, p. 270). El que necesita radicalmente el saber no sólo es el que lo descubre y lo crea sino además el que cuestiona todo saber que se presenta como ya dado. El que de verdad no lo necesita y sólo lo estudia, se conformará con el saber que se encuentra ya hecho. La necesidad vital por tanto es madre de la ciencia y también de la crítica. En suma, concluye Ortega (1933, p. 268), “una Revista Tópicos Educacionais, Pernambuco, v. 27, n. 01, p. 136-153, 2021. ISSN: 2448-0215. https://periodicos.ufpe.br/revistas/topicoseducacionais/index DOI: 10.51359/2448-0215.2021.249623 
verdad no existe propiamente sino para quien la ha menester; que una ciencia no es tal ciencia sino para quien la busca afanoso", lo que implica que para quien no la necesita y, por tanto, no la busca, esa ciencia no es sino una serie de ideas en el fondo sin sentido. Por muy verdadero que sea lo que estudiamos desde un punto de vista objetivo, el hecho mismo de estudiar es una falsedad subjetivo/vital porque significa buscar verdades que no necesitamos. Por esto no tenía ningún sentido pedagógico decir (enseñar) una verdad, sino sólo ayudar a descubrirla reexperimentando el hecho de necesitarla y buscarla, porque sólo así la aprendemos realmente. El alumno solo aprende de verdad si vive el saber, si descubre esos contenidos, si vive la experiencia del descubrimiento.

Tan rechazable como el intelectualismo lo es también su opuesto, el vitalismo radical, que justifica la verdad y objetividad de una tesis por sus consecuencias vitales. Esta supeditación de la verdad a la vitalidad se ejemplifica en el prejuicio que hace creer que el sufrimiento legitima la objetividad de una causa: el hecho de que alguien dé su vida por una causa parece avalar la verdad de esa causa. Contra esta postura que convierte el dolor -la vida- en garante del valor objetivo de una idea, Nietzsche argumenta que pensar que "los mártires demuestran algo para la verdad es algo tan poco verdadero que podría negar que en general nunca un mártir haya tenido nada que ver con la verdad", y esto se debe a que erróneamente se ha asumido que "con la sangre se demuestra la verdad"; pero, añade, "la sangre es el peor testigo de la verdad", y "si alguien caminase a través del fuego por su doctrina, iqué demuestra eso! Mejor sería verdaderamente que de su propio incendio extrajese su propia doctrina" (NIETZSCHE, 1889b, p. 235). Contra el vitalismo, la experiencia vital no justifica la verdad; lo que hay que hacer, frente al intelectualismo, es extraer ésta de aquélla. El saber debe proceder de la experiencia vivida, pero el valor de verdad de ese saber es independiente de esa fundación vital. Efectivamente, según la posición antiintelectualista adoptada por Ortega (1933, pp. 273s), "la cultura o saber no tiene más realidad que responder y satisfacer en una u otra medida a necesidades efectivamente sentidas". Pero esto no implica la desaparición de la verdad objetiva. Sin fundamento vital, el saber es pura abstracción, pero el saber no podrá atender a las necesidades vitales sin pensar la verdad y atenerse a la objetividad. Ortega confirma que "no puedo pensar con utilidad para mis fines biológicos, si no pienso la verdad. Un pensamiento que normalmente nos presentase un mundo divergente del verdadero, nos llevaría a constantes errores prácticos" (ORTEGA, 1923, p. 580). La verdad sólo existe para el que la necesita, pero no es verdad porque la necesite. La verdad sólo puede ser descubierta y tener sentido para el que la necesita, pero precisamente por ello, lo que necesita es que sea verdadera y objetiva. La vida no justifica la verdad -o falsedad- objetiva de los contenidos, pero sin vínculo Revista Tópicos Educacionais, Pernambuco, v. 27, n. 01, p. 136-153, 2021. ISSN: 2448-0215. https://periodicos.ufpe.br/revistas/topicoseducacionais/index DOI: $10.51359 / 2448-0215.2021 .249623$ 
vital los contenidos son puras abstracciones, distantes y momificadas. Por tanto, el vitalismo de la pedagogía orteguiana no es radical puesto que no afecta al carácter de verdad de los contenidos, que, a diferencia del vitalismo radical, es independiente de la vitalidad, sino sólo a su descubrimiento.

Asumido este principio pedagógico vitalista, es natural que Ortega defienda que "el estudiar es en sí mismo algo humanamente falso", pues "para que yo entienda de verdad una ciencia no basta que yo finja en mí la necesidad de ella, no basta que tenga la voluntad de aceptarla; en fin, no basta con que estudie. Es preciso, además, que sienta auténticamente su necesidad, que me preocupen espontánea y verdaderamente sus cuestiones; sólo así entenderé las soluciones que ella da o pretende dar a esas cuestiones. Mal puede nadie entender una respuesta cuando no ha sentido la pregunta a que ella responde" (ORTEGA, 1933, pp. 273ss). No es suficiente ser un buen estudiante para apropiarse del saber: hay que sentir auténtica o vitalmente la necesidad de ese saber. Por tanto, lejos de suprimir el estudio, algo absurdo, Ortega considera preciso trasformar el método pedagógico para que, ya que es natural que la mayoría de las personas no sientan auténticamente la necesidad que llevó a los creadores a sus respectivos descubrimientos, pueden llegar a sentirla mediante la enseñanza. Se trata, en palabras de Ortega (1933, p. 275), de "reformar profundamente ese hacer humano que es el estudiar y, con ello, el ser del estudiante. Para esto es preciso volver del revés la enseñanza: enseñar no es fundamentalmente sino enseñar la necesidad de una ciencia, y no enseñar la ciencia cuya necesidad sea imposible hacer sentir al estudiante". Inspirado en el socratismo pedagógico, así culmina el método educativo de la pedagogía de la alusión: nunca debe tener por meta principal enseñar contenidos sino enseñar la necesidad del saber, porque una vez que logremos hacerla sentir el alumno aprenderá de verdad, ya que buscará entonces el saber que ya sí necesita. Y no hay mejor manera de aprender que buscar por uno mismo.

\section{Pedagogía crítico/creativa del descubrimiento}

Sólo sabe de verdad el que busca porque sólo él descubre y crea. Pero sólo busca el que siente la necesidad de descubrir, de pensar. Sin esta necesidad libre que surge del interior del sujeto no hay posibilidad de descubrir - pensar- nada. Por tanto, esta pedagogía nos invita a revivir en clase la experiencia descubridora/creadora del pensar. "Así enseño yo. ¡Y sólo para crear (Schaffen) debéis aprender!”, escribe Nietzsche (1885, p. 258). La pedagogía socrática de la alusión y el descubrimiento resulta ser una pedagogía de la creatividad. El espíritu de la creación Revista Tópicos Educacionais, Pernambuco, v. 27, n. 01, p. 136-153, 2021. ISSN: 2448-0215. https://periodicos.ufpe.br/revistas/topicoseducacionais/index DOI: $10.51359 / 2448-0215.2021 .249623$ 
implica según Nietzsche trascender lo dado y por tanto superarse a sí mismo. Ya que "la vida tiene que superarse (überwinden) continuamente a sí misma", Nietzsche confiesa: "Yo amo a quien quiere crear (schaffen) por encima de sí mismo" (NIETZSCHE, 1885, pp. 130, 84). La meta de esta pedagogía es afirmar el espíritu crítico, lo que implica estimular la creación, porque la única crítica verdaderamente tal es la creatividad. Sólo quien crea se rebela de verdad contra lo establecido. Lejos de esto y a pesar de las explícitas declaraciones en favor del carácter crítico y creativo de nuestra pedagogía, la enseñanza actual está sometida por una ética utilitarista del rendimiento, también en las humanidades, de modo que el resultado práctico y útil se establece como criterio educativo. En el fondo sólo se promociona massmediáticamente aquella enseñanza que contribuye al progreso y bienestar material. No condenamos lógicamente la educación científica y utilitarista. Pero de nada vale esta enseñanza científico-técnica sin la formación humanista, que cada vez es más necesaria frente al poder de aquella ética productiva. Ya Aristóteles, al plantearse cómo ha de educarse, se cuestionaba "si conviene atender más a la inteligencia que al carácter del alma", y concluía que "no está nada claro si deben practicarse las disciplinas útiles para la vida o las que tienden a la virtud" (ARISTÓTELES, 1988, 1337a 39-43, p. 457). En la época del imperio del pragmatismo hay que reivindicar el cuidado humanista del alma porque sin ella nos convertiríamos en meros seres humanos de hecho, sin humanidad.

Heidegger señala que "lo decisivo está en la trasformación (Umdeutung) del espíritu (Geist) en inteligencia (Intelligenz), concebida como mera capacidad de entender, mediante la reflexión, el cálculo y la observación, las cosas dadas de antemano", de manera que "el espíritu, así falsificado en inteligencia, se degrada hasta desempeñar el papel de instrumento y su manejo es susceptible de enseñarse y aprenderse” (HEIDEGGER, 1935, p. 50). Esta instrumentalización del espíritu ha convertido la educación en útil al servicio de la voluntad de poder que controla y manipula, mediante la inserción del saber en el sistema de dominio técnico/práctico extirpando así su dimensión pensante, constitutivamente crítico/creativa. Frente a aquella enseñanza pragmática, que se pliega y se adapta a lo establecido porque de entrada es lo más útil, el rasgo principal de esta educación humanista debe ser el fortalecimiento del espíritu creativo y descubridor.

Aunque como nos recuerda Ortega (1930, p. 551) "la ciencia es sólo investigación", creación, y "no es ciencia aprender una ciencia o enseñarla", la actividad pedagógica logrará su objetivo de enseñar con autenticidad esa ciencia si reproduce el acto creativo de descubrimiento. No se pretende que el alumno sea un científico sino de que entienda su ciencia reviviendo él mismo, desde dentro, la creatividad descubridora que dio lugar a esa ciencia. Sólo así aprenderá. Revista Tópicos Educacionais, Pernambuco, v. 27, n. 01, p. 136-153, 2021. ISSN: 2448-0215. https://periodicos.ufpe.br/revistas/topicoseducacionais/index DOI: 10.51359/2448-0215.2021.249623 
No obstante y aunque las proclamas expresas vayan en sentido contrario, un gran problema de la educación actual es la primacía de la categoría de adaptación, opuesta a la libre reflexión creativa, verdadera base de la cultura europea. Es una educación unidimensional, consecuencia según Marcuse del actualmente dominante "modelo de pensamiento y conducta unidimensional (pattern of one-dimensional thought and behavior) en el que ideas, aspiraciones y objetivos que trascienden por su contenido el universo establecido del discurso y la acción, son rechazados o reducidos a los términos de este universo" (MARCUSE, 1964, p. 14). De hecho, contra esta "liquidación de la cultura bidimensional (two-dimensional culture)" que abría "otra dimensión de la realidad" más allá de la ya establecida (MARCUSE, 1964, pp. 60, 107), es necesaria una educación bidimensional. La cultura europea ha surgido del ensayo y el error, del riesgo y el peligro. Sin ensayar no hay creatividad. En vez de adaptación, de respeto a lo dado y seguimiento irrestricto de reglas, la educación debe enseñar a pensar, esto es, a ensayar, a arriesgarse. ¿Puede haber aprendizaje, pensamiento, sin riesgo?. Sólo se aprende cuando arriesgamos y nos equivocamos. Gadamer (2000, p. 49) se pregunta "¿quién ha aprendido realmente si no ha aprendido de sus propios errores?". Esto es lo humano y lo que debemos enseñar en lugar de maquinizarnos y maquinizar la educación.

\section{La pedagogía de la pregunta}

La materia pedagógica se refiere al enseñar y al aprender. Desde una perspectiva lógica, de lo que se trata en ella es de saber para poder enseñar y de aprender para llegar a saber. Aristóteles $(1994,981 b$, p. 73$)$ ha sostenido que "el ser capaz de enseñar es una señal distintiva del que sabe frente al que no sabe”. La lógica del sentido común afirma que el que sabe enseña, y el que no enseña es que realmente no sabe. Ser capaz de enseñar es una señal que diferencia al que sabe del que no sabe. Aristóteles enriquece esta tesis al escribir que "toda ciencia parece ser susceptible de ser enseñada, y todo lo que es objeto de ella de ser aprendido" (ARISTÓTELES, 1959, 1139b, p. 91). Todo aquello que se sabe se puede enseñar y todo lo que es sabido se puede aprender. El enseñar deviene entonces criterio del saber. Pero esta tesis presupone una comprensión del saber como posesión de contenidos. Esto implica que es imposible penetrar filosóficamente en el problema del enseñar y el aprender sin plantearse con radicalidad la pregunta por el saber. Toda teoría pedagógica presupone una determinada idea del saber. La meta de la docencia es que el alumno sepa. Ahora bien, qué es saber. Heidegger señala que el "tener simplemente conocimientos (Kenntnisse), por amplios que sean, no es saber (Wissen) en modo alguno", pues saber Revista Tópicos Educacionais, Pernambuco, v. 27, n. 01, p. 136-153, 2021. ISSN: 2448-0215. https://periodicos.ufpe.br/revistas/topicoseducacionais/index DOI: $10.51359 / 2448-0215.2021 .249623$ 
rigurosamente significa para él "poder sostenerse (stehen können) en la verdad (Wahrheit)" (HEIDEGGER, 1935, p. 23). Saber no es el mero disponer de unos conocimientos, sino desvelar la verdad, medirse con las cosas para revelar su ser, o sea, pensar. Saber es descubrir. Heidegger (1935, p. 24) subraya que

"saber significa poder aprender (lernen können). El entendimiento común piensa ciertamente que los que saben son aquellos que no necesitan aprender, puesto que ya han terminado su aprendizaje. Pero no es así; sólo sabe aquel que entiende que debe volver a aprender constantemente y el que, a raíz de esta comprensión, haya llegado ante todo a la posición de poder aprender siempre".

Saber es poder aprender porque, de acuerdo con el sólo sé que no sé nada socrático, la docta ignorantia cusana, el que sabe lo que realmente sabe es que no sabe y que ha de aprender. Sólo sabe el que sabe que siempre ha de aprender porque conoce la finitud humana y que, en consecuencia, nunca sabemos del todo, nunca sabemos de tal manera que ya no necesitamos seguir aprendiendo. Esta conciencia es justo la que le permite aprender, pues sólo aprende el que sabe que no sabe.

Recordemos que según Aristóteles sólo puede enseñar el que sabe. Aunque parece que el que sabe no necesita preguntar ni aprender, y el que pregunta no sabe, realmente saber ya no significa poseer una doctrina, el mero disponer de unos conocimientos y no tener ya que aprender, sino saber que no se sabe y por tanto 'poder aprender', lo que supone, según Heidegger (1935, p. 24), "poder preguntar (Fragenkönnen)", o sea, "querer saber". Sólo sabe el que sabe que el saber no es poseer ya unos conocimientos, de manera que lo que sabe el que auténticamente sabe es que siempre debe aprender. Sólo aprende el que pregunta, el que sabe que no sabe. El preguntar es la esencia del saber porque supone saber algo aquello que no sabe. Este saber de lo que no se sabe es la condición de posibilidad del preguntar -y del saber humano, siempre finito y en proceso sin fin. Saber de verdad, esto es, saber que no se sabe, significa seguir preguntando, pues, escribe Gadamer (1960, p. 369), “el que está seguro de saberlo todo no puede preguntar (fragen) nada. Para poder preguntar hay que querer saber, es decir, saber (wissen) que no se sabe". Sólo pregunta el que sabe que no sabe. Por eso preguntar no es fácil. Es un arte: "No hay método (Methode) que enseñe a preguntar (fragen zu lernen)", asegura Gadamer (1960, p. 371). Si se pregunta es porque se quiere saber y porque se sabe que no se sabe. Saber preguntar es el arte más difícil porque para llegar a ese no saber y preguntar hay que estar al tiempo en los dos lados, en el saber y el no-saber: “preguntar es más difícil (schwerer) que responder (Antworten)" (GADAMER, 1960, p. 368). Mientras se pregunta se tiene conciencia de no saber, pero esto mismo y no otra cosa es poner en Revista Tópicos Educacionais, Pernambuco, v. 27, n. 01, p. 136-153, 2021. ISSN: 2448-0215. https://periodicos.ufpe.br/revistas/topicoseducacionais/index 
práctica el arte de pensar: "El arte de preguntar es el arte de seguir preguntando (Kunst des Weiterfragens), y esto significa que es el arte de pensar (Denkens)" (GADAMER, 1960, p. 372). El preguntar entonces no es un simple paso previo hacia el saber, como si éste residiera exclusivamente en la respuesta. Heidegger sostiene que "el preguntar se convertirá en la suprema figura (Gestalt) del saber" (HEIDEGGER, 1933, p. 111). Preguntar es la clave del saber porque, según Gadamer, sólo sabemos o entendemos algo cuando encontramos la pregunta a la que responde aquello que pretendíamos entender: "Sólo comprendemos cuando comprendemos la pregunta para que algo es respuesta (Antwort)", de modo que "comprender una opinión (Meinung) quiere decir entenderla como respuesta a una pregunta" (GADAMER, 1960, pp. 380s). Saber significa entonces esencialmente hallar la pregunta, descubrir y plantear preguntas. Buscar las preguntas a las que responde lo que queremos entender (saber), es el método pedagógico idóneo. La pauta que gobierna a la buena pedagogía es la que lo considera todo desde la perspectiva de la pregunta, no desde la respuesta, desde el contenido doctrinario. Las respuestas sólo pueden ser comprendidas desde el descubrimiento de la pregunta. Y dado que lo que busca el aprender es saber, comprender, entonces aprender un contenido consistirá en descubrir la pregunta a la que dicho contenido responde.

\section{Enseñar el aprender}

Esta respuesta socrática a la pregunta filosófica por el saber tiene relevantes consecuencias pedagógicas que afectan a aquella lógica del sentido común relación expuesta entre el enseñar y el aprender. Sócrates ya mostró que para que el alumno aprenda y sepa no se le pueden dar los contenidos sin más, pues sólo sabe cuando él mismo aprende descubriendo lo que ha de aprender. El simple estudiar impuesto desde fuera es el enemigo del verdadero aprender. Por eso, recordemos, Gadamer afirmaba que la educación es educarse, que "nos educamos a nosotros mismos y el llamado educador participa tan solo con una modesta contribución" (GADAMER, 2000 , p. 16). No obstante, esta 'modesta contribución' es esencial y el propio Gadamer (2000, p. 41) lo reconoce al añadir que lo decisivo en la educación es que se le dé al alumno "la capacidad de corregir sus propias deficiencias de saber a través de su propia actividad". Esta capacidad de corregirse, decisiva pedagógicamente, es la tarea principal del enseñar que realiza el maestro. Pero en el enseñar no se ofrece al alumno lo por aprender sino que se le da la indicación para aprenderlo (descubrirlo) por sí mismo. Cuando el alumno recibe sin más lo ofrecido no aprende. El aprender es un descubrir, algo que se da el alumno a sí mismo. Hay que enseñarle a ser creativo, a Revista Tópicos Educacionais, Pernambuco, v. 27, n. 01, p. 136-153, 2021. ISSN: 2448-0215. https://periodicos.ufpe.br/revistas/topicoseducacionais/index DOI: $10.51359 / 2448-0215.2021 .249623$ 
descubrir, a pensar por él mismo, porque sólo así aprenderá de verdad. Para que el alumno aprenda desde dentro, desde él mismo, el enseñar no puede consistir en el simple trasmitir contenidos sino en dejar aprender, en enseñar al alumno a aprender por sí mismo. Esto es lo que debe enseñar el auténtico enseñar: el aprender. Por ello, el maestro en vez de trasmitir saber debe dar la indicación mediante la pregunta para que el alumno descubra el saber y aprenda.

En esta tarea el maestro ayuda aludiendo, o sea, iniciando el gesto que debe culminar el alumno con el descubrimiento de la verdad correspondiente. De acuerdo con el texto fundamental de Ortega, Heidegger insiste en que "enseñar (Lehren) es un dar (Geben), ofrecer (Darbieten): pero en el enseñar no se ofrece lo aprendible (Lernbare) sino sólo la indicación (Anweisung) al alumno de tomar por sí mismo", de modo que "el alumno no aprende si se limita a recibir (übernimmt) lo ofrecido" (HEIDEGGER, 1935/36, p. 73). El verdadero aprender sólo sucede cuando el alumno tiene la experiencia de tomar por sí mismo el contenido, de descubrirlo y apropiárselo. Es como un darse a sí mismo. Por tanto, subraya Heidegger (1935/36, pp. 73s), “enseñar sólo significa dejar aprender a los otros (Anderen lernen lassen)". Realmente, "el verdadero maestro (Lehrer) no deja aprender nada más que el aprender (Lernen)" (HEIDEGGER, 1951/52, pp. 17s). Cuando el maestro alude a un contenido iniciando el gesto interrogativo del pensar para que el alumno lo complete con su actividad descubridora, lo que verdaderamente está enseñando es el aprender. De ahí que, si comprendemos el aprender como obtención de conocimientos, produzca la impresión de que propiamente no se aprende nada con ese maestro socrático. Sólo enseña ayudando al alumno a aprender, a pensar. Gilson afirmó que "aunque los profesores no pueden pensar por nosotros, pueden sin embargo hacernos pensar por nosotros mismos, o al menos ayudarnos a hacerlo" (GILSON, 1960, p. 38). La única forma de enseñar es enseñar a aprender, para que el alumno aprenda por sí mismo, único modo auténtico de aprender. Esto significa que el objetivo de toda auténtica pedagogía no es tanto dar contenidos como educar el intelecto del alumno para que él mismo sepa cómo descubrirlos. Así lo expuso Descartes (1628, I, p. 61): "El fin de los estudios debe ser la dirección del espíritu para que emita juicios sólidos y verdaderos de todo lo que se le presente". Esto es lo que hacía Sócrates con su método mayéutico de las preguntas, ayudar al alumno a alumbrar por sí mismo los pensamientos. El arte de la pregunta es el método de esta pedagogía de la alusión y el descubrimiento. Lejos de dar contenidos, enseñar entonces es situar mediante preguntas al alumno en la posición intelectual exacta para que los descubra por sí mismo. Sólo así, desde dentro, puede realmente aprender. Sólo se aprende desde uno mismo y dirigido por preguntas, no desde fuera, no mediante la donación Revista Tópicos Educacionais, Pernambuco, v. 27, n. 01, p. 136-153, 2021. ISSN: 2448-0215. https://periodicos.ufpe.br/revistas/topicoseducacionais/index DOI: 10.51359/2448-0215.2021.249623 
externa de contenidos. Sobre todo preguntar, pero también responder. El buen maestro es el que sabe preguntar porque así conduce al alumno a que responda bien, esto es, a que descubra. Siguiendo a Sócrates, Gadamer (2000, p. 10) concluye que "sólo se puede aprender mediante la conversación (Gespräch)".

\section{Enseñar es más difícil que aprender}

Ahora bien, para enseñar el aprender, el maestro tiene que aprender él mismo al enseñar. Sólo el que puede aprender deja aprender, enseña el aprender, porque el que cree saberlo todo enseña magistocéntricamente lo que ya sabe y no el aprender. Tiene que revivir la experiencia del aprender, del descubrimiento de conocimientos, y así es como enseña. No hay otra forma de enseñar el aprender que aprendiendo él mismo. El maestro enseña con el ejemplo, debe volver a ser estudiante. Esta pedagogía socrática obliga al maestro a volver a descubrir el saber, a pensar en suma. Así es como logra aludir, indicar y activar el movimiento de aprendizaje del alumno para que él mismo lo culmine. Para el maestro entonces, enseñar equivale a aprender. Reviviendo el aprender -la experiencia del pensar descubridor planteándose preguntas-, enseña. Sólo puede enseñar el que, al enseñar, aprende. Para poder enseñar hay que poder aprender. Lo enseñado puede ser algo pensado, sabido, y de hecho suele serlo. No importa. Lo relevante es que no se puede dar como doctrina sabida y trasmitida sino que hay pensarla de nuevo y descubrirla, aprenderla en suma. Cuando el maestro hace esto y aprende, entonces enseña. Sólo aprendiendo él, logra que el alumno aprenda. Entonces, sólo el que puede aprender, el que pregunta, puede enseñar. El auténtico enseñar, el que de verdad enseña, presupone el aprender. El enseñar contiene el aprender y sólo en tanto aprende enseña. De ahí que Dewey pudiera sostener que "el maestro es un aprendiz (teacher is a learner), y el aprendiz, sin saberlo, es un maestro" (DEWEY, 1916, p. 167). Pero entonces "el maestro posee respecto de los alumnos (Lehrlingen) como único privilegio el que tiene que aprender mucho más que ellos: el dejar-aprender (Lernen-lassen)" (HEIDEGGER, 1951/52, p. 18). De ahí que la mayor capacidad para aprender, con más propiedad, es lo que diferencia al maestro de los alumnos. Heidegger (1935/36, p. 74) sentencia que "en todo enseñar quien más aprende es el maestro”. Al enseñar, el que más aprende es el que enseña. Cuando el maestro es el que más aprende, entonces enseña de verdad. Este sería el criterio y el síntoma de una buena enseñanza. Y aprende mejor porque sabe mejor, esto es, porque sabe que no sabe y que tiene que aprender constantemente. Contra la tesis magistocéntrica del profesor dominador del saber y seguro de sus conocimientos que impone al alumno, esto quiere decir que en la verdadera Revista Tópicos Educacionais, Pernambuco, v. 27, n. 01, p. 136-153, 2021. ISSN: 2448-0215. https://periodicos.ufpe.br/revistas/topicoseducacionais/index DOI: 10.51359/2448-0215.2021.249623 
relación entre maestro y alumno, en palabras de Heidegger (1951/52, p. 18), "nunca entra en juego la autoridad del sabelotodo (Viel-Wisser) ni la influencia autoritaria (autoritative Einfluß)". Por ello "enseñar es más difícil que aprender", advierte Heidegger (1951/52, p. 17), y "no porque el maestro deba poseer una mayor cantidad de conocimientos", no porque tenga que saber más para enseñar al que no sabe, sino porque ha de saber en el sentido del poder aprender, pues "sólo quien de verdad puede aprender -y sólo mientras pueda hacerlo- puede enseñar" (HEIDEGGER, 1935/36, p. 74). Si se piensa que enseñar no es más difícil que aprender es porque se presupone que enseñar implica ya saber en el sentido de no necesitar aprender. Pero entonces no se enseña el aprender sino lógicamente todo aquello que ya se sabe. Sólo el maestro socrático, que sabe que no sabe, enseña lo esencial y lo más difícil: el aprender.

\section{Conclusión}

Aunque la educación desde dentro coloca al alumno en el centro, esta pedagogía paidocéntrica plantea al maestro la más alta exigencia: tener que seguir siendo maestro en el paidocentrismo. Esto supone un enseñar paidocéntrico, que es lo que practicaba Sócrates. El maestro debe enseñar con conciencia de que el alumno y el aprender representan el centro pedagógico. Para lograr enseñar y, al tiempo, evitar trasmitir sin más contenidos, el maestro tiene que enseñar el aprender, y lo enseña reviviendo él mismo el descubrir y el aprender mediante el método del preguntar. Así cumple con su función pedagógica y enseña, pero sin enseñar, puesto que no da contenidos, sino que al enseñar el aprender permite que sea el alumno, como núcleo del acto educativo, quien descubra (aprenda) por sí mismo los contenidos. En la educación paidocéntrica el maestro sólo puede enseñar a aprender. Esto es lo más difícil y lo más sublime, lo único que lo convierte en verdadero maestro.

\section{Referencias}

ARISTÓTELES. Ética a Nicómaco. Madrid, Instituto de Estudios Políticos, 1959. . Política. Madrid, Gredos, 1988. . Metafisica. Madrid, Gredos, 1994.

DESCARTES, R. (1628) Reglas para la dirección del espíritu. Madrid, Alianza, 1996,

DEWEY, J. (1897) My Pedagogic Creed. En E. F. Provenzo (ed.), Critical Issues in Education. An Anthology of Readings. Thousand Oaks, CA, Sage, 2006.

. (1912/13) "Philosophy of Education". The Middle Works of John Dewey 1899-1924, v.

7. Carbondale, Southern Illinois University Press, 1979.

Revista Tópicos Educacionais, Pernambuco, v. 27, n. 01, p. 136-153, 2021. ISSN: 2448-0215.

https://periodicos.ufpe.br/revistas/topicoseducacionais/index

DOI: 10.51359/2448-0215.2021.249623 
(1916) Democracy and Education. The Middle Works of John Dewey 1899-1924, v. 9.

Carbondale, Southern Illinois University Press, 1980.

(1929) The Sources of a Science of Education. The Later Works of John Dewey 1925-

1953, vol. 5. Carbondale, Southern Illinois University Press, 2008.

GADAMER, H-G. (1960) Hermeneutik I. Wahrheit und Methode. Gesammelte Werke, Band 1.

Tübingen, Mohr (Siebeck), 1990.

. Erziehung ist sich erziehen. Heidelberg, Kurpfälzischer, 2000.

GARCÍA AMILBURU, M. y GARCÍA GUTIÉRREZ, J. Filosofía de la educación. Cuestiones de hoy y de siempre. Madrid, Uned-Narcea, 2012.

GILSON, É. (1960) El amor a la sabiduría. Madrid, Rialp, 2015.

HEIDEGGER, M. (1933) Die Selbstbehauptung der deutschen Universität. Gesamtausgabe, Band 16. Frankfurt a. M. Klostermann, 2000.

. (1935) Einführung in die Metaphysik. Gesamtausgabe, Band 40, 1983.

. (1935/36) Die Frage nach dem Ding. Gesamtausgabe, Band 41, 1984.

. (1951/52) Was heisst Denken? Gesamtausgabe, Band 8, 2002.

(1952) “Was heisst Denken?". Gesamtausgabe, Band 7, 2000.

KANT, I. (1765) Pädagogik. Kants Werke, Akademie Textausgabe, Band IX. Berlin, Walter de Gruyter, 1968

. (1787) Kritik der reinen Vernunft, 2. Auflage. Kants Werke, Band III.

LESSING, G. E. (1780) Die Erziehung des Menschengeschlechts. Werke, Achter Band:

Theologiekritische Schriften III / Philosophische Schriften. München, Carl Hanser, 1979.

MARCUSE, H. (1964) One-Dimensional Man. London and New York, Routledge, 2002.

NIETZSCHE, F. (1885) Also sprach Zarathustra. Kritische Studienausgabe, Band 4. München, De Gruyter, 1980.

. (1889a) Götzen-Dämmerung oder Wie man mit dem Hammer philosophirt. Kritische Studienausgabe, Band 6.

. (1889b) Der Antichrist. Fluch auf das Christenthum. Kritische Studienausgabe, Band 6.

ORTEGA Y GASSET, J. (1914) Meditaciones del Quijote. Obras Completas, t. I. Madrid, Fundación Ortega/Taurus, 2004.

. (1923) El tema de nuestro tiempo. OC, t. III, 2005.

(1930) Misión de la Universidad. OC, t. IV, 2005.

(1932) Pidiendo un Goethe desde dentro. OC, t. V, 2006.

(1933) "Sobre el estudiar y el estudiante". $O C$, t. V.

PLATÓN. Apología de Sócrates, Diálogos, I. Madrid, Gredos, 1985.

SCHOPENHAUER, A. (1851) Parerga y paralipómena, t. II. Madrid, Trotta, 2013.

UNAMUNO, M. (1899) De la enseñanza superior en España. Obras Completas, t. III. Madrid, Afrodisio Aguado, 1958.

. (1900) "La ideocracia". OC, t. III.

(1902) "La educación". OC, t. III.

Revista Tópicos Educacionais, Pernambuco, v. 27, n. 01, p. 136-153, 2021. ISSN: 2448-0215.

https://periodicos.ufpe.br/revistas/topicoseducacionais/index

DOI: 10.51359/2448-0215.2021.249623 
Revista Tópicos Educacionais

Revista do Programa de Pós-Graduação em Educação

da Universidade Federal de Pernambuco (UFPE)

. (1912) Del sentiientom trágico de la vida. OC, t. XVI.

Recebido em março de 2021.

Aprovado em maio de 2021.

Revista Tópicos Educacionais, Pernambuco, v. 27, n. 01, p. 136-153, 2021. ISSN: 2448-0215.

https://periodicos.ufpe.br/revistas/topicoseducacionais/index 